\title{
Design and Simulation Analysis of Modal and Harmonic Response of Chained Deep-ploughing Device
}

\author{
Fu-gui Zhang ${ }^{* 1}$, Wei Wei ${ }^{2}$, Xue-mei $\mathrm{Wu}^{3}{ }^{3}$ YaoNie ${ }^{4}$, Gui-fu $\mathrm{Xu}^{5}$, and De-Long \\ $\mathrm{Fu}^{6}$ \\ ${ }^{1}$ Colleage of Mechanical Engineering, Guizhou University, Guiyang 550025, China \\ ${ }^{2}$ Colleage of Mechanical Engineering, Guizhou University, Guiyang 550025, China \\ ${ }^{3}$ Colleage of Mechanical Engineering, Guizhou University, Guiyang 550025, China \\ ${ }^{4}$ Colleage of Mechanical Engineering, Guizhou University, Guiyang 550025, China \\ ${ }^{5}$ Colleage of Mechanical Engineering, Guizhou University, Guiyang 550025, China \\ ${ }^{6}$ Bijie Branch of Guizhou Provincial Tobacco Corporation, Bijie 551700, China \\ ${ }^{*}$ Corresponding author
}

Keyword: Chained Deep-ploughing, Design, Modal, Harmonic Response

\begin{abstract}
In light of complex topography in southern mountain area, a small chained deep-ploughing machine with crawler was developed. Its key part was a chained deep-ploughing device, whose service life could be impacted by vibration frequency as well as strength and rigidity of the material used. This paper presented the design of the chained deep-ploughing device and related kinematics and mechanical analyses. With the help of finite unit method and Ansys Workbench, simulation analysis of modal and harmonic response was conducted. Modal and vibration mode of the first six orders concluded verified the fact that the deep ploughing device was able to avoid resonance and meet requirements for deep ploughing. This also provided basis for other dynamic response.
\end{abstract}

\section{Introduction}

Mini tillers were widely used in southern mountain area for many years, in which situation, harden plow pan was formed under shallow plough layer, impacting the deep growth of root system and making it difficult for water and fertilizer to penetrate, among others[1,2]. In recent years, different kinds of improved small deep-ploughing machines have been developed, where two of them are chained deep-ploughing machine, whose intellectual property rights are held by Southwest University (2014) and Zunyi Branch of Guizhou Tobacco Company (2014), respectively. The one held by Southwest University is a small walking deep-ploughing machine with crawler: with help of link span, chained deep-ploughing parts are linked to crawler machinery and fixed to a rectangle frame formed by two crawler units, engine and rack of crawler machinery[3]. The other one is a deep-ploughing machine: rotary cutter is linked to both chains and the largest ploughing depth is determined by the distance and dip angle between main chain wheel and the driven chain wheel[4]. The problem that rests in both of these two chained deep-ploughing machines is that they have complexly structured chained deep-ploughing devices. However, the chained deep-ploughing device applicable for small deep-ploughing machine designed here is simply structured. According to kinematics and mechanical analyses and simulation analysis of modal and harmonic response, the device designed here was able to avoid resonance and meet requirements for deep ploughing[5]. 


\section{Basic Structure of Chained Deep-ploughing Device}

Structure of chained deep-ploughing device is indicated in Figure 1. It consists of 1 driving chain wheel, 2 chain, 3 chain cutter, 4 driven chain wheel, 5 work arm, among others. It is an agricultural device that ploughs with multiple chain cutters and is also the core device for small chained deep-ploughing machine with crawler. The engine controls chained deep-ploughing device through gearbox and then gear case and hydraulic control system. When wheels walk towards to the same direction as the chain transmission shaft, the deep ploughing function of this device is on; otherwise, ditching function is on.

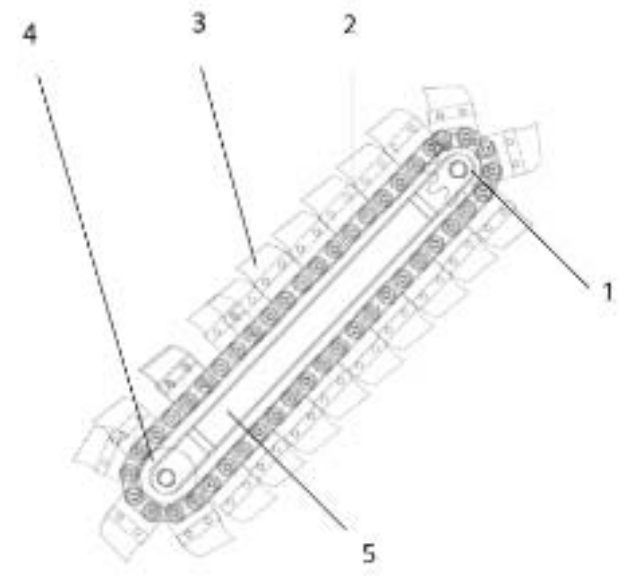

Fig. 1 Structure of Chained Deep-ploughing Device

\section{Parameters Calculation of Chained Deep-ploughing Device}

When chained deep-ploughing device performs deep ploughing lengthwise, due to dynamic loading acted on chain cutter and abrasion caused by cutting soil, minor waggle will inevitably happen to chain cutter and impacts the speed. In general, in order to guarantee the quality of operation of chained deep-ploughing device, the minor waggle mentioned herein shall be reduced as far as possible. As a result, linear velocity of chain cutter needs to be limited when it is designed: generally, for mineral soil, the speed $\mathrm{Vc}$ is $1.0-2.0 \mathrm{~m} / \mathrm{s}$ and for peat soil, the speed $\mathrm{Vc}$ is $3.0-4.0 \mathrm{~m} / \mathrm{s}[6]$.

Based on kinematics and related geometric principles (see Figure 2), the following equation can be developed with the help of relevant literature[7].

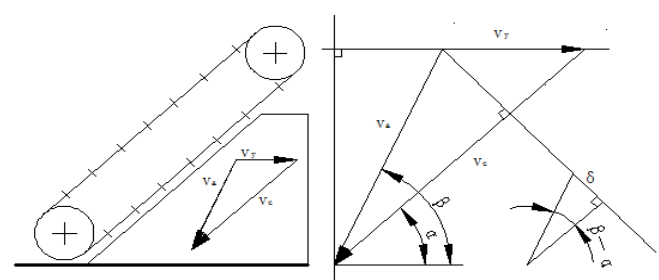

Fig. 2 Kinematics Analysis of Chained Deep-ploughing Device

Horizontal velocity of working parts of chain cutter is determined by the productivity of the machine and the sectional area of the cutting groove.

For equation: 


$$
V_{y}=\frac{\eta}{3.6 \times 10^{3} b_{g d} Z_{\mathrm{c}}} \quad(\mathrm{m} / \mathrm{s})
$$

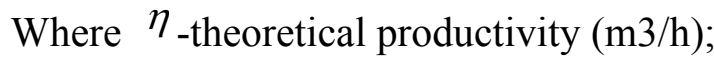

b g d-ploughing width (m);

$\mathrm{Z}$ c-ploughing depth (m).

Dip angle from the level was set as $45^{\circ}$ at design time.

The absolute velocity of chain cutter $V_{a}$ :

$$
V_{a}=\sqrt{V_{c}^{2}+V_{y}^{2}-2 v_{c} V_{y} \cos \alpha}(\mathrm{m} / \mathrm{s})
$$

Where $V c$-velocity of chain cutter $(\mathrm{m} / \mathrm{s})$;

$V_{y}$-operation velocity of working parts of the chain cutter $(\mathrm{m} / \mathrm{s})$;

$\alpha$-dip angle of the working chain cutter from the level.

The dip angle $\beta$ of absolute motion velocity vector $V$ a can be obtained from equation (1-3):

$$
\operatorname{tg} \beta=\frac{V_{\mathrm{c}} \sin \alpha}{V_{\mathrm{c}} \cos \alpha-V_{\mathrm{y}}}
$$

According to equation (1-3), $\beta$ equals $42^{\circ}$ 。

Generally, height of chain cutter hc is $0.1-0.15 \mathrm{~m}$. However, if the height increases, the loading of the working parts rises. As a result, the height of chain cutter he in this paper is $0.1 \mathrm{~m}$.

Preliminary computation can be conducted for cutting thickness $\delta$ based on chain cutter pitch Lc:

$$
\delta=L_{\mathrm{c}} \sin (\beta-\alpha)
$$

And the following equation can be used instead under rational soil cutting condition:

$$
\delta \approx \frac{\mathrm{b}_{\mathrm{c}}}{10^{\sim} 15} \quad(\mathrm{~m})
$$

In this paper, chain cutter pitch Lc is $50.8 \mathrm{~mm}$ and based on equation (1-4), cutting thickness of chain cutter $\delta$ is $5.83 \mathrm{~mm}$. According to equation (1-5), cutter width $b_{c}$ is $87.6 \mathrm{~mm}$.

Delivery capacity shall be verified for the preselected scraper height and pitch. Choose proper chain cutter height hc and cutter width bc.

hc and bc shall meet the following requirements:

$$
\eta \leq \eta^{\prime} \frac{1}{\mathrm{k}_{\mathrm{d}}} \lambda
$$

Where $\eta_{-}$the given productivity $(\mathrm{m} 3 / \mathrm{h})$

$\eta^{\prime}$ - productivity of chain cutter-type working parts on basis of discharge capacity (m3/h)

$\mathrm{k}_{\mathrm{d}}$ - loose coefficient of soil

$\lambda$ - scattering coefficient related to kinematic velocity of chain. See the following table for more details: 


\begin{tabular}{|c|c|c|c|c|}
\hline $\mathrm{V}_{\mathrm{c}}(\mathrm{m} / \mathrm{s})$ & 0.1 & 1 & 1.5 & 2 \\
\hline$\lambda$ & 0.97 & 0.92 & 0.85 & 0.75 \\
\hline
\end{tabular}

Calculate the productivity $\eta^{\prime}$ of chain cutter-type working parts under the following conditions: If

$$
\alpha \leq \varphi+\operatorname{arctg} \frac{h_{\mathrm{c}}}{L_{\mathrm{c}}}
$$

Where $\varphi^{\varphi}$-natural angle of repose of loos soil

h c- height of chain cutter $(\mathrm{m})$

Lc- blade pitch (m)

$$
\eta^{\prime}=360 \omega_{\mathrm{c}} \mathrm{h}_{\mathrm{c}} V_{\mathrm{c}}\left[1-\frac{L_{\mathrm{c}}}{2 \mathrm{~h}_{\mathrm{c}}} \operatorname{tg}(\alpha-\beta)\right]
$$

If $\alpha \leq \varphi+\operatorname{arctg} \frac{h_{\mathrm{c}}}{L_{\mathrm{c}}}$, soil transferred is shaped as triangle

$$
\eta^{\prime}=3600 b_{\mathrm{c}} h_{\mathrm{c}} V_{\mathrm{c}} \frac{\mathrm{h}_{\mathrm{c}} \operatorname{tg}(\alpha-\varphi)}{2 L_{\mathrm{c}}}
$$

If $\alpha \leq \varphi$, chain cutter-type working parts have the maximum productivity:

$$
\eta^{\prime}=3600 \mathrm{~b}_{\mathrm{c}} \mathrm{h}_{\mathrm{c}} V_{\mathrm{c}} \quad(\mathrm{m} 3 / \mathrm{h})
$$

Natural angle of repose of loos soil is the maximum dip angle for avoiding slop failure under natural soil conditions. Under actual condition, tester of angle of repose may be used. In light of the actual operation of deep-ploughing machine, the angle of repose was set at $30^{\circ}$. The cross-reference table given below indicates the most commonly used angle of repose for soil[8].

i.e.

In this paper, since $\alpha_{\mathrm{s}}=45^{\circ}$, and

$$
\varphi+\operatorname{arctg} \frac{h_{\mathrm{c}}}{L_{\mathrm{c}}=30+} \operatorname{arctg} \frac{100}{50.8} \approx 93^{\circ},
$$

$$
\alpha_{\mathrm{s}} \leq \varphi+\operatorname{arctg} \frac{\mathrm{h}_{\mathrm{c}}}{L_{\mathrm{c}}}
$$

per equation (1-7).

After computation, equation (1-7) meets the relation

$$
\eta \leq \eta^{\prime} \frac{1}{\mathrm{k}_{\mathrm{d}}} \lambda
$$


Table 1 Natural angle of repose of soil

\begin{tabular}{|c|c|c|c|}
\hline Soil type & $\begin{array}{c}\text { Degree(s) under wet } \\
\text { condition }\end{array}$ & $\begin{array}{c}\text { Degree(s) under humid } \\
\text { condition }\end{array}$ & $\begin{array}{c}\text { Degree(s) under dry } \\
\text { condition }\end{array}$ \\
\hline Coarse sand & 27 & 32 & 30 \\
\hline $\begin{array}{c}\text { Medium } \\
\text { sand }\end{array}$ & 25 & 35 & 28 \\
\hline Gravel & 35 & 40 & 40 \\
\hline Scree & 35 & 40 & 25 \\
\hline Silver sand & 20 & 30 & 45 \\
\hline Gault & 15 & 35 & 45 \\
\hline Humus & 25 & 35 & 50 \\
\hline Light clay & 30 & 40 & 40 \\
\hline Light loam & 20 & 30 & 35 \\
\hline Fill soil & 27 & 45 & \\
\hline
\end{tabular}

\section{Mechanical Analysis of Chained Deep-ploughing Device-Calculation of Cutting Resistance for Chain Cutter}

When small chained deep-ploughing machine with crawler is in operation, soil scraps produced by each chain cutter have different shape, which are the basis for calculating ploughing resistance and productivity. The shape of soil scraps are related to the structure of chain cutter of ditcher. For B-type chain cutter, the resistance produced by cutting soil can be computed as follows:

$$
F_{\mathrm{t}}^{\prime}=9.8 \mathrm{I}_{\mathrm{tu}} \delta^{1.35}\left(1+0.1 \delta_{\mathrm{c}}\right) \quad\left(-\frac{90^{\circ}-\psi}{180}\right) \mathrm{e}
$$

Where I t u- impact value of firmness concluded by the former Soviet Union Road Science Institute (see Table 2)

$\delta$ - cutting thickness (mm);

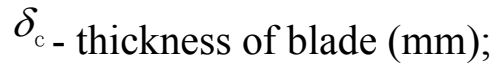

$\psi$ - cutting angle of blade $\left(^{\circ}\right)$;

e- cofficient of edge angle $\gamma$ (see Table 3).

Table $2 \mathrm{I}_{\mathrm{tu}}$ Value

\begin{tabular}{|l|l|l|l|l|l|l|l|}
\hline Item & \multicolumn{1}{|l|}{$\begin{array}{l}\text { Boggy and } \\
\text { peat soil }\end{array}$} & $\begin{array}{l}\text { Sandy } \\
\text { soil }\end{array}$ & $\begin{array}{l}\text { Sandy } \\
\text { loam }\end{array}$ & Loam & Heavy loam & Clay & Heavy clay \\
\hline $\mathrm{I}_{\text {tu }}$ & $1 \curvearrowright 5$ & $1 \approx 4$ & $3 \_12$ & $5^{\curvearrowright} 10$ & $9 \curvearrowright 18$ & $14 \curvearrowright 19$ & $18 \curvearrowright 24$ \\
\hline
\end{tabular}


Table $3 \gamma$ and $\mathrm{e}$ values

\begin{tabular}{|l|c|l|l|l|l|}
\hline$\gamma$ & $15^{\circ} \sim 50^{\circ}$ & $60^{\circ}$ & $90^{\circ}$ & $120^{\circ}$ & $180^{\circ}$ \\
\hline $\mathrm{e}$ & 0.81 & 0.83 & 0.90 & 0.95 & 1.0 \\
\hline
\end{tabular}

The total resistance for ditching $F_{\mathrm{k}}^{\prime}$ is calculated based on total cutting force acted on soil simultaneously. The force acted on the chain by $F_{\mathrm{k}}^{\prime}$ :

$$
F_{\mathrm{k}}^{\prime}=F_{\mathrm{t}}^{\prime} Z_{\mathrm{t}}{ }^{\prime}
$$

Where $F_{\mathrm{t}}^{\prime}$-resistance produced from cutting soil $(\mathrm{N})$;

$$
Z_{\mathrm{t}}^{\prime} \text {-number of blades acting on soil. }
$$

Based on equation (1-10), resistance produced from cutting soil to each chain cutter $F_{\mathrm{t}}{ }^{\prime}=341 \mathrm{~N}$ $\left(Z_{\mathrm{t}}^{\prime}=4\right)$ and the total resistance caused by cutting to the deep-ploughing machine $F_{\mathrm{k}}^{\prime}=1364 \mathrm{~N}$.

\section{Finite Element Model of Chained Deep-ploughing Device}

Modal analysis is mainly used for determining the inherent frequency and mode of vibration of the structure[9]. As in small chained deep-ploughing machine with crawler' case, it's the movement of chain wheel that drives the movement of chain of chain cutter. Vibration produced by chain cutter by entering and cutting soil and meshing of chain link and sprocket cause bumpy motion and regular vibration to chain drive. Therefore, for the purpose of keeping chained deep-ploughing device away from the vibrational frequency of deep-ploughing machine, and also for avoiding resonance happening to the structure and improving the structural stability, launching modal analysis and finding out the inherent frequency mentioned herein are very necessary[10].

Modal analysis solving in Ansys Workbench was completed by Pre-Stress Modal within Custom Systems module. For the purpose of modal analysis, Modal Analysis System would be added to the Project Flow in the first place and materials, models and other data were shared with static analysis. When modal analysis was conducted for the overall structure of small chained deep-ploughing machine with crawler in this paper, axle of drive sprocket was fixed on the rack of chained deep-ploughing machine in light of the actual situation and as a result, fixed constraint needed to be added to the work arm near axle of drive sprocket to limit constraints of all directions and add constraint for force. See Figure 3 for more details. 


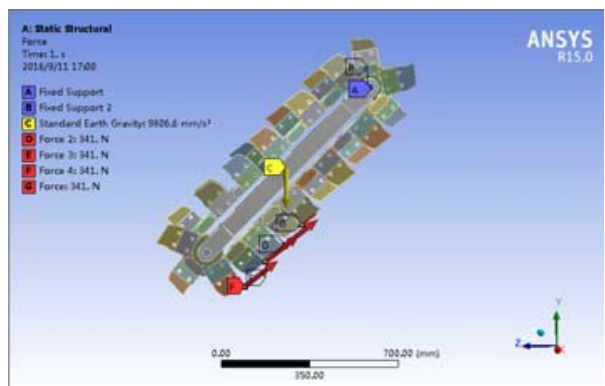

Figure 3 Geometric Model of Modal and Harmonic Response Analysis

\section{Result and Discussion}

\section{Finite Element Model of Chained Deep-ploughing Device}

Any structure may have many orders for their inherent frequency. However, for large mechanical structure, it is generally low-order inherent frequency that has important impact on the structure and high-order mode has little impact on most structures[11]. This paper analyzes soil cutting process of chained deep-ploughing machine and discusses inherent frequencies of the first six orders.

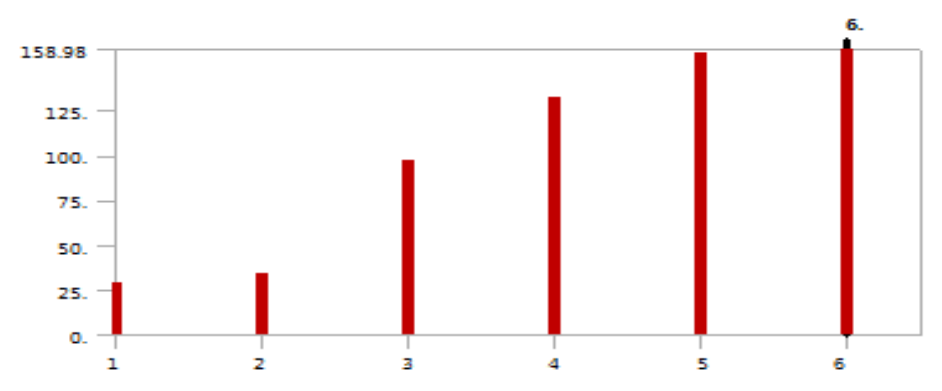

Figure 4 Analysis of inherent frequency of the first six-order modal of deep-ploughing deviceModal frequencies of the first six orders of deep-ploughing machine provided in Figure 4 are $28.578 \mathrm{~Hz}, 33.9271 \mathrm{~Hz}, 96.684 \mathrm{~Hz}, 132.41 \mathrm{~Hz}$, $156.83 \mathrm{~Hz}$ and $158.98 \mathrm{~Hz}$.

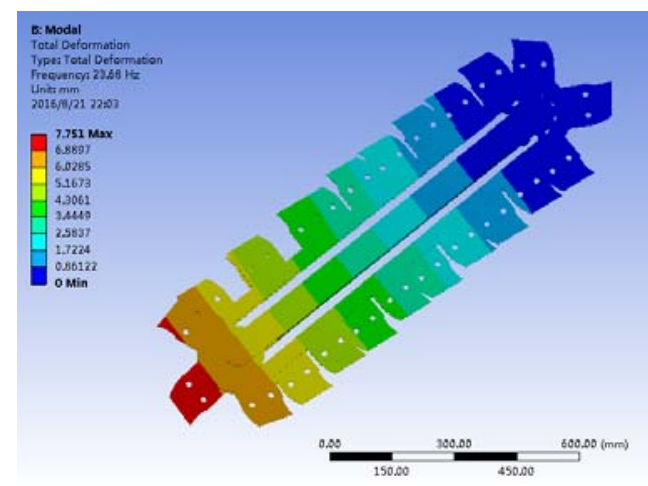

(a) Plot of the first order mode of vibration of chained deep-ploughing machine

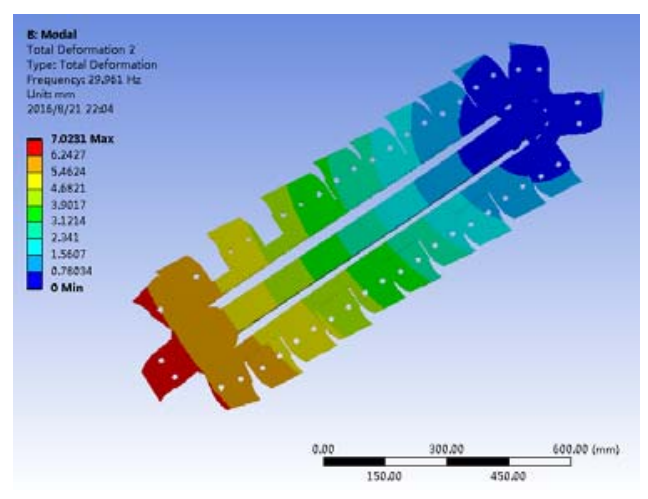

(b) Plot of the second order mode of vibration of chained deep-ploughing machine 


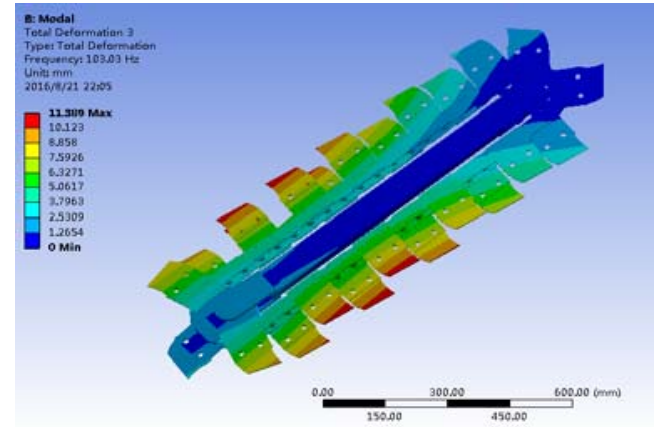

(c) Plot of the third order mode of vibration of chained deep-ploughing machine

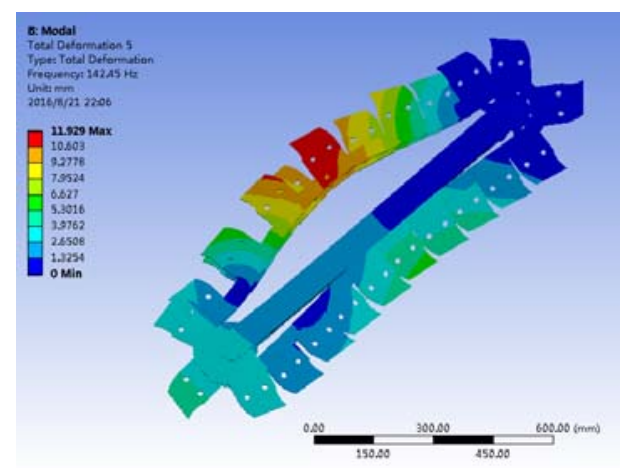

(e) Plot of the fifth order mode of vibration of chained deep-ploughing machine

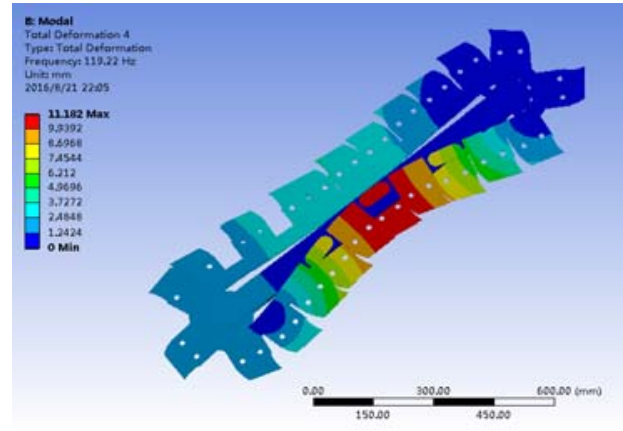

(d) Plot of the fourth order mode of vibration of chained deep-ploughing machine

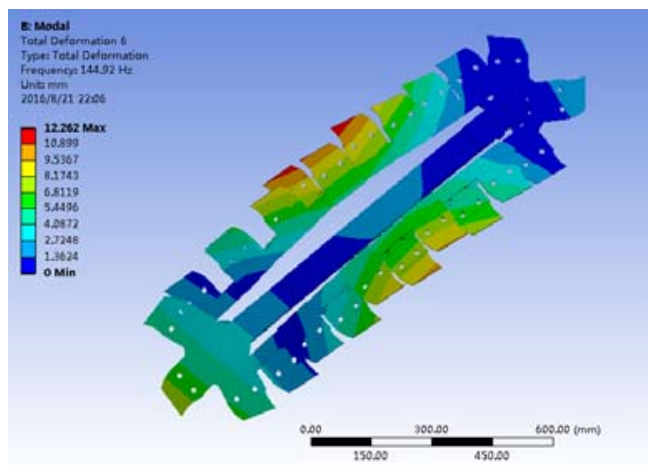

(f) Plot of the sixth order mode of vibration of chained deep-ploughing machine

Fig. 5 Plots of inherent frequency of each order mode

After modal analysis of chained seep-ploughing device of small chained deep-ploughing machine with crawler, plots of inherent frequencies of the first six orders for chained deep-ploughing machine are obtained. See Figure 5 for more details.

Modes of vibration of chained deep-ploughing device are now presented as follows:

The first order mode of vibration of chained deep-ploughing device is indicated in Figure (5a). Drive sprocket is taken as the center of chained deep-ploughing device in this case with the end of work arm as the maximum swing. The maximum deformation is found at the chain cutter at the end of driven sprocket.

The second order mode of vibration of chained deep-ploughing device is indicated in Figure (5b). In this case, the maximum swing is found at the end of work arm of chained deep-ploughing device. Same as the first order mode of vibration, the maximum deformation is found at the chain cutter at the end of driven sprocket.

The third order mode of vibration of chained deep-ploughing device is indicated in Figure (5c). In this case, the mode of vibration is the axial wobble of the whole chained deep-ploughing device. The maximum deformation is found in between the up and down chain links in the middle of chain drive.

The fourth order mode of vibration of chained deep-ploughing device is indicated in Figure (5d). The mode of vibration is the transverse vibration of the lower chain. The maximum deformation is found in the middle of the lower chain of chain drive.

The fifth order mode of vibration of chained deep-ploughing device is indicated in Figure (5e). 
The mode of vibration is the transverse vibration of the upper chain. The maximum deformation is found in the middle of the upper chain of chain drive.

The sixth order mode of vibration of chained deep-ploughing device is indicated in Figure (5f). The mode of vibration is the axial wobble of the whole chained deep-ploughing device. The maximum deformation is found in between the up and down chain links in the middle of chain drive, mainly at the upper part.

The design requirements for chained deep-ploughing device of small chained deep-ploughing machine with crawler are that modal frequency of chained deep-ploughing device shall be kept away from the excitation frequency of load. Generally, lots of excitation vibration sources may cause vibration to chained deep-ploughing device, where the main sources are unbalanced wheels of walking tractor and unbalanced load exerted on chained deep-ploughing device, among others.

According to relevant research data, excitation frequency caused by unbalanced wheel of walking tractor is very low, most of them lower than $10 \mathrm{~Hz}$. Therefore, the impact imposed by it is overlooked in this paper. Vibration caused by the unbalanced load carried by chain cutter of chained deep-ploughing device is the main excitation source. As a result, the inherent frequency of chained deep-ploughing device designed should stay away from excitation frequency in order to achieve good dynamic behavior for chained deep-ploughing device.

\section{Harmonic Response Analysis}

The inherent modal frequency and mode of vibration of the first six orders of chained deep-ploughing device were concluded through modal analysis of finite element model of chained deep-ploughing device of small chained deep-ploughing machined with crawler. When deep-ploughing machine is in operation, due to the meshing of roller chain and chain wheel caused by chain transmission, impact effect can be generated regularly. When meshing frequency is almost the same as the inherent frequency of chained deep-ploughing device, resonance happens[12]. And for this reason, when kinetic study is conducted for chained deep-ploughing device of deep-ploughing machine, the all-sided kinetic characteristics of chained deep-ploughing device cannot be achieved only through modal analysis and the harmonic response of chained deep-ploughing device shall also be studied. The relationship between dynamic response and frequency of chained deep-ploughing device will be analyzed to find out if chained deep-ploughing device of deep-ploughing machine can avoid resonance when it's in operation.

\section{Computation of Working Frequency}

Periodical impact force, i.e. the excitation force acted on chain drive, is determined by amplitude, phase position and forced vibration frequency. Namely, when chained deep-ploughing machine is in operation, the chain cutter will generate impact effect and its frequency is:

$$
\mathrm{f}=\frac{\mathrm{V}_{\mathrm{c}}}{\mathrm{P}}=\frac{1500}{50.8}=29.5 \mathrm{~Hz}
$$

Where V c- linear velocity of chain ( $\mathrm{mm} / \mathrm{s})$; P-pitch of links chains (mm).

\section{Process Before Harmonic Response Analysis}

Harmonic response analysis was conducted by Harmonic Response within Mechanical module of ANSYS Workbench. For the purpose of harmonic response analysis, Harmonic Response Analysis System would be added to the Project Flow in the first place and materials, models and modal analysis results were shared with modal analysis. 
Forcing frequency range of structural system must be designated when harmonic response analysis is conducted. In this paper, according to modal analysis results, frequencies of chained deep-ploughing device of the first six orders were lower than $160 \mathrm{~Hz}$ and therefore, the forcing frequency range shall be designated at $0-160 \mathrm{~Hz}$ when harmonic response was conducted and set 40 solutions.

\section{Results of Harmonic Response Analysis}

Mode superposition method was used for model solving after set based on parameters mentioned above. This way, harmonic response analysis results of chained deep-ploughing device of chained deep-ploughing machine were reached.

Figure 6 and Figure 7 show the stress-frequency response curve of chained deep-ploughing device and deformation-frequency curve of chained deep-ploughing device, respectively. Big stress responses and deformation responses can be seen when the frequencies are $30 \mathrm{~Hz}, 95 \mathrm{~Hz}, 135 \mathrm{~Hz}$ and $156 \mathrm{~Hz}$, which are close to the inherent frequencies of chained deep-ploughing device. Given the fact that $30 \mathrm{~Hz}, 95 \mathrm{~Hz}, 135 \mathrm{~Hz}$ and $156 \mathrm{~Hz}$ are close to the inherent frequencies of the first, the second, the third, the fourth and the fifth orders, it agrees with the results of modal analysis.

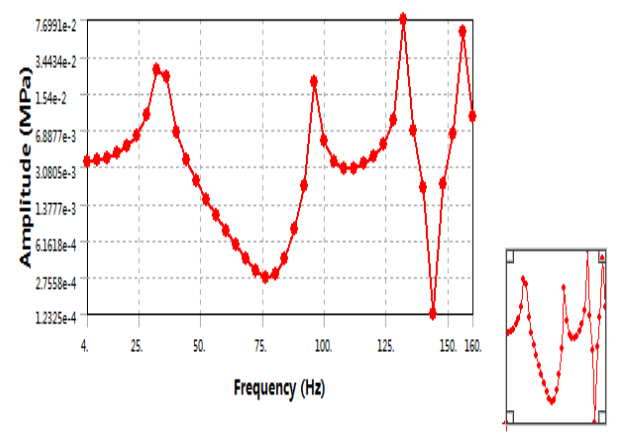

Fig.6 Stress-frequency Curve of Deep-ploughing Device

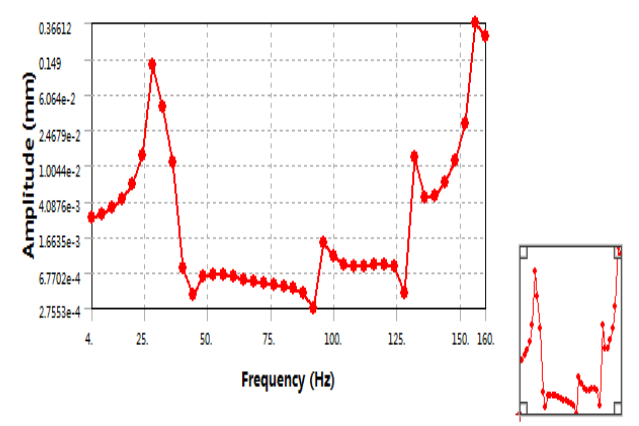

Fig.7 Deformation-frequency Response of Deep-ploughing Device

Note that antiresonance point of chained deep-ploughing device appeared at around $140 \mathrm{~Hz}$. This was antiresonance caused by superposition of excitation force and inherent frequency of chained deep-ploughing device. When the device was at this frequency, the resonance effect of chained deep-ploughing device could be avoided.

The inherent frequency of chained deep-ploughing device used in this paper was $29.5 \mathrm{~Hz}$ and based on analysis above, it could be concluded that the chained deep-ploughing device avoided the inherent frequency at this point, which prevented the appearance of resonance. 


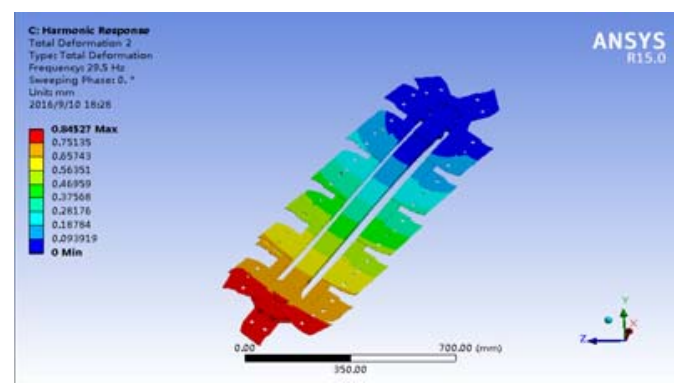

Fig.8 Deformation Analysis under Working

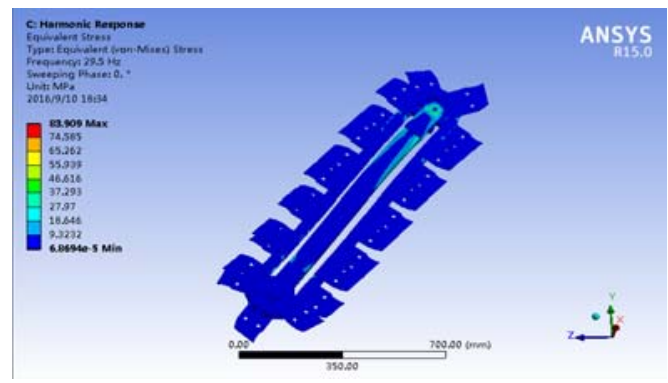

Fig. 9 Stress Analysis under Working Frequency

Frequency

Figure 8 shows the deformation analysis of chained deep-ploughing device at frequency of $29.5 \mathrm{~Hz}$. According to Figure 8, the maximum deformation for the working frequency of chained deep-ploughing device was $0.84527 \mathrm{~mm}$, which had no impact on deep ploughing. Figure 9 shows the stress analysis of chained deep-ploughing device at frequency of $29.5 \mathrm{~Hz}$. According to Figure 9, the maximum stress for the working frequency of chained deep-ploughing device was $83.909 \mathrm{Mpa}$.

\section{Theoretical Analysis of Strength and Stiffness of Deep-ploughing Device}

Intensity examination of deep-ploughing device: the maximum stress of chained deep-ploughing device at working frequency was $83.909 \mathrm{Mpa}$. The main materials used for the deep-ploughing device of deep-ploughing machine were 45 steel and $45 \mathrm{Mn}$ and their yield limit were $355 \mathrm{MPa}$ and $375 \mathrm{Mpa}$, respectively. According to analysis results, the maximum stress for the working frequency of chained deep-ploughing device was far lower than the yield limit of materials used. Therefore, the deep-ploughing device designed in this paper agreed with strength requirements.

Stiffness examination of deep-ploughing device: the whole deep-ploughing device could be taken as a cantilever beam structure when displacement analysis was conducted. Given that the total length of the beam $\mathrm{L}=920 \mathrm{~mm}$ and based on the following equation[13]:

$$
\begin{aligned}
& \mathrm{y}=\left|\frac{F L \quad{ }^{3}}{3 E I}\right| \\
& \mathrm{F}=\mathrm{P} / \mathrm{V}
\end{aligned}
$$

y- deflection (mm);

E- elasticity modulus of material $\mathrm{E}=210 \mathrm{GPa}$;

I- inertia moment of rectangular steel $\mathrm{I}=\frac{\mathrm{hb}{ }^{3}}{12}$ (h and $\mathrm{b}$ are the height and width of the rectangular steel);

P- engine power $(\mathrm{w})$;

V- walking velocity of deep-ploughing machine $(\mathrm{m} / \mathrm{s})$;

F-Traction of deep-ploughing machine, i.e. force acted on the cantilever beam $(\mathrm{N})$.

Based on equation (3-2) and (3-3), deflections y are $0.8472 \mathrm{~mm}$ and $0.0009 \mathrm{~L}$, which are close to the maximum deformation of chained deep-ploughing device at working frequency and verified the reliability of simulation. Given the allowable deflection of cantilever beam $[y]=0.002 \mathrm{~L}$, it can be 
concluded that the deflection of deep-ploughing device is lower than the allowable one. In another word, deep-ploughing device meets stiffness requirements.

Given that the excitation frequency of chained deep-ploughing device designed avoided its own inherent frequency, resonance of the structure could be kept away effectively. No major stress and deformation might appear at the working frequency of chained deep-ploughing device and the strength and stiffness of the structure had enough allowance, which met requirements for deep ploughing.

\section{Conclusions}

Based on analyses above, the following conclusions can be reached:

(1)Based on the modal analysis of chained deep-ploughing device of small chained deep-ploughing machine with crawler, inherent frequencies of the first six orders were obtained, which were helpful for the deep-ploughing device to achieve good dynamic behavior.

(2)Based on harmonic response analysis, the stress-frequency and deformation-frequency curves of chained deep-ploughing device were obtained and the frequencies that had big impact on chained deep-ploughing device were found out, which were helpful for deep-ploughing machine to avoid these frequencies and provided powerful basis for the improvement and optimization of chained deep-ploughing device. It was at working frequency of $29.5 \mathrm{~Hz}$ that the chained deep-ploughing device of small chained deep-ploughing machine with crawler avoided resonance. Also at this working frequency, the maximum stress and the deformation of the device was $83.909 \mathrm{Mpa}$ and $0.84527 \mathrm{~mm}$ respectively, meeting requirements for deep ploughing.

(3)This paper provided new thoughts for the development of small chained deep-ploughing machine and basis for seeking for sensitive position and structure optimization for chained deep-ploughing device[14].

\section{Acknowledgment}

This work was financed by the Major special project of Guizhou: Research and Demonstration of Integration of Quality Tobacco Machine and Agricultural Technology (QKHZDZX [2014] 6015-6), the Science and technology project of Bijie Branch, Guizhou Tobacco Corporation: Adaptive optimization design research of Commonly used models of Bijie tobacco machinery(GYBK[2015]3) and the Science and technology project of Bijie Branch, Guizhou Tobacco Corporation: Research and Application of Deep Ploughing Technology in Tobacco Field with Different Soils in Bijie (201652050024140).

\section{References}

[1]Chen Jian,Chen Chuan,Chen Hong. Three New Challenges Micro Tillers Face in Southwest China and Study of Countermeasures[J]. Journal of Agricultural, 2014,10:245-248.

[2]AnđelkoButorac, Jasminka Butorac,Ivica Kisić. Systems of conservation tillage in Europe[J]. Agronomy journal,2006,68(1):43-55.

[3]He Peixiang,Kang Jie,He Jiahui,et al. A small walking type caterpillar chain deep tillage machine[P].Chong Qing: CN103814634A,2014-05-28.

[4] Zhu Zhongbin,He Peixiang,Chen Yiping,et al. A deep tillage[P].Gui Zhou: CN203537757U,2014-04-16. 
[5]Li Yaoming,Sun Pengpeng,Pang Jing,et al.Finite element mode analysis and experiment of combine harvester chassis[J]. Transactions of the Chinese Society of Agricultural Engineering, 2013,03:38-46+301

[6] Zeng Dengchao. Mechanical soil dynamics[M].Bei Jing: Beijing Science and Technology Press, 1995.

[7] Zhang Xiaoan. Agricultural machinery design manual[k].Bei Jing: China's Agricultural Science and Technology Press,2007.

[8]Fang Enhong. Research of Chain ditcher design method[A master's degree thesis][D], Jilin university,2006.

[9]Yao Yanchun,Du Yuefeng,Zhu Zhongxiang,et al.Vibration characteristics analysis and optimization of corn combine harvester frame using modal analysis method[J]. Transactions of the Chinese Society of Agricultural Engineering, 2015,19:46-53.

[10]Li Zongfa,Tong Shuiguang,Wang Xiangbing.Dynamic Optimization Design for Working Device of Hydraulic Excavator Based on Modal Analysis[J]. Transactions of the Chinese Society for Agricultural Machinery, 2014,04:28-36.

[11]Gong Hanyang, Wang Liquan, Xing Xiaodong, et al. Modeling of the plow body of submarine plowing trencher and analysis of the soil cutting process[J]. Journal of Mechanical Engineering, 2012, 48 (19) 134-140.

[12]Ren Wei, Wang Yunchao.Study on the dynamic characteristics fortrenching implement of chain-type trencher[J]. Construction machinery, 2005, (11): 77-81.

[13]Ge Xinxin. Engineering mechanics, mechanics of materials[M].BeiJing:Higher Education Press,2008.

[14Liu Xuanwei,Jin Liang,Wang Jingli. Modal Analysis of the Frame of Subsoiler Based on ANSYS Workbench[J]. Journal of Agricultural, 2015,05:29-31+35. 